\title{
MANAJEMEN LINTAS BUDAYA
}

\author{
Suryanto $^{1}$
}

\begin{abstract}
This article explains about globalization versus national resposiveness matrix, meeting the challenge, cross cultural differences and similiarities, parochialism and simplification, also cultural differences in selected countries and regions. The purpose of the research is to find factor, method, strategy in order to bridging management across cultural, so that a manager can have a better view in making a decision based on cultural differences and need of the company. From this article can be concluded that there are four factor that must be consider in Multi National Company (MNC). Those factors are (1) It's important to be divided in worldwide standard; (2) It's important to differennate product at the local market; (3) It's important to have insider; (4) there is one more contribution to local condition. In order to succeed in MNC, a company must survive from across cultural threat, there are parodialism and simplification.
\end{abstract}

Keywords: management, cultural

\section{ABSTRAK}

Artikel memaparkan globalization versus national resposiveness matrix, meeting the challenge, cross cultural differences and similiarities, parochialism and simplification, also cultural differences in selected countries and regions. Tujuan penelitian untuk menemukan faktor, metode, strategi untuk menjembatani manajemen lintas budaya sehingga manajer memperoleh pandangan dalam membuat keputusan berdasarkan lintas budaya dan kebutuhan perusahaan. Dari artikel ini dapat disimpulkan bahwa terdapat empat faktor yang harus dipertimbangkan dalam Multi National Company (MNC). Keempat faktor tersebut adalah (1) perlu dibagi dalam standar worldwide; (2) pentingnya diferensiasikan produk untuk pasar lokal; (3) perlunya menjadi orang dalam daripada tergantung kebijakan ekspor; dan (4) perlunya memberikan sumbangan yang lebih berarti untuk merespons kondisi lokal.

Kata kunci: manajemen, budaya

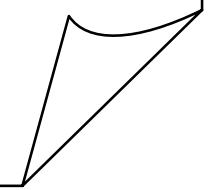

\footnotetext{
${ }^{1}$ Staf Pengajar, Fakultas Ekonomi, UBiNus, Jakarta
} 


\section{PENDAHULUAN}

Pengetahuan tentang persamaan dan perbedaan kebudayaan semakin penting bagi keberhasilan strategi suatu perusahaan multinasional Multi National Company (MNC), jika perusahaan menjadi transnational. Sebagai contoh, Asea Brown Boveri (ABB), suatu perusahaan raksasa internasional yang terbentuk dari hasil merger perusahaan Swedia, Jerman, dan Swiss. Meskipun kantor pusatnya terletak di kota Zurich, Swiss, MNC itu mempunyai kegiatan di seluruh dunia. Selama dua dekade ini, perusahaan itu telah mengambil alih lebih dari 60 perusahaan, termasuk perusahaan di Amerika seperti Combution Engineering yang terkenal dalam pembuatan power generation dan proses automation equipment. Selain memproduksi kereta api di Swedia, ABB juga mempunyai product line yang luas termasuk robot, peralatan listrik, peralatan reaksi termonuklir, dan peralatan rumah sakit. Karena bisnis global, MNC harus menyeimbangkan antara kepentingan globalisasi dengan kepentingan lokal atau kawasan (regional).

Baru-baru ini, ABB memenangkan kontrak pembuatan kereta api untuk India. Dua negara yang bersedia memberikan kredit untuk pembuatan kereta api ini adalah Jerman dan Italia karena ABB mempunyai perusahaan komponen kereta api di kedua negara tersebut. Contoh itu mengilustrasikan salah satu masalah besar yang dihadapi MNC dalam managing across border, yaitu kecenderungan alamiah untuk mengerjakan sesuatu di negara lain dengan cara yang sama di negeri asalnya. Biasanya pada strategi manajemen internasional dikenal sebagai globalization versus national responsiveness conflict.

\section{PEMBAHASAN}

\section{Globalization Versus National Responsiveness Matrix}

Isu ini dapat dianalisis secara konseptual dengan matrix dua dimensi sebagai berikut.

Sumbu vertikal dalam gambar tersebut mengukur kebutuhan integrasi ekonomi, biasa disebut globalisasi. Pergerakan ke atas sumbu vertikal menunjukkan makin besarnya derajat integrasi ekonomi. Globalisasi menghasilkan skala ekonomi yang besar dan membutuhkan modal yang akan menurunkan biaya per unit jika perusahaan telah berhasil menjual produk atau jasanya pada pasar dunia. Globalisasi dicapai dengan mensentralisasi aktivitas tertentu dalam meningkatkan nilai tambahnya. Selain itu, dengan meningkatkan koordinasi dan kontrol atas aktivitas menyebar sesuai dengan geografik.

Sumbu horisontal mengukur kebutuhan MNC untuk merespon pada national responsiveness atau diferensiasi. Sumbu ini menunjukkan seberapa besar MNC harus mengarah pada selera lokal dan peraturan pemerintah. Hasilnya, mungkin menyebabkan penyebaran aktivitas secara geografik atau desentralisasi koordinasi dan kontrol untuk setiap MNC. Gambar di bawah ini menggambarkan empat situasi dasar yang berhubungan tingkat globalization versus national responsiveness. 


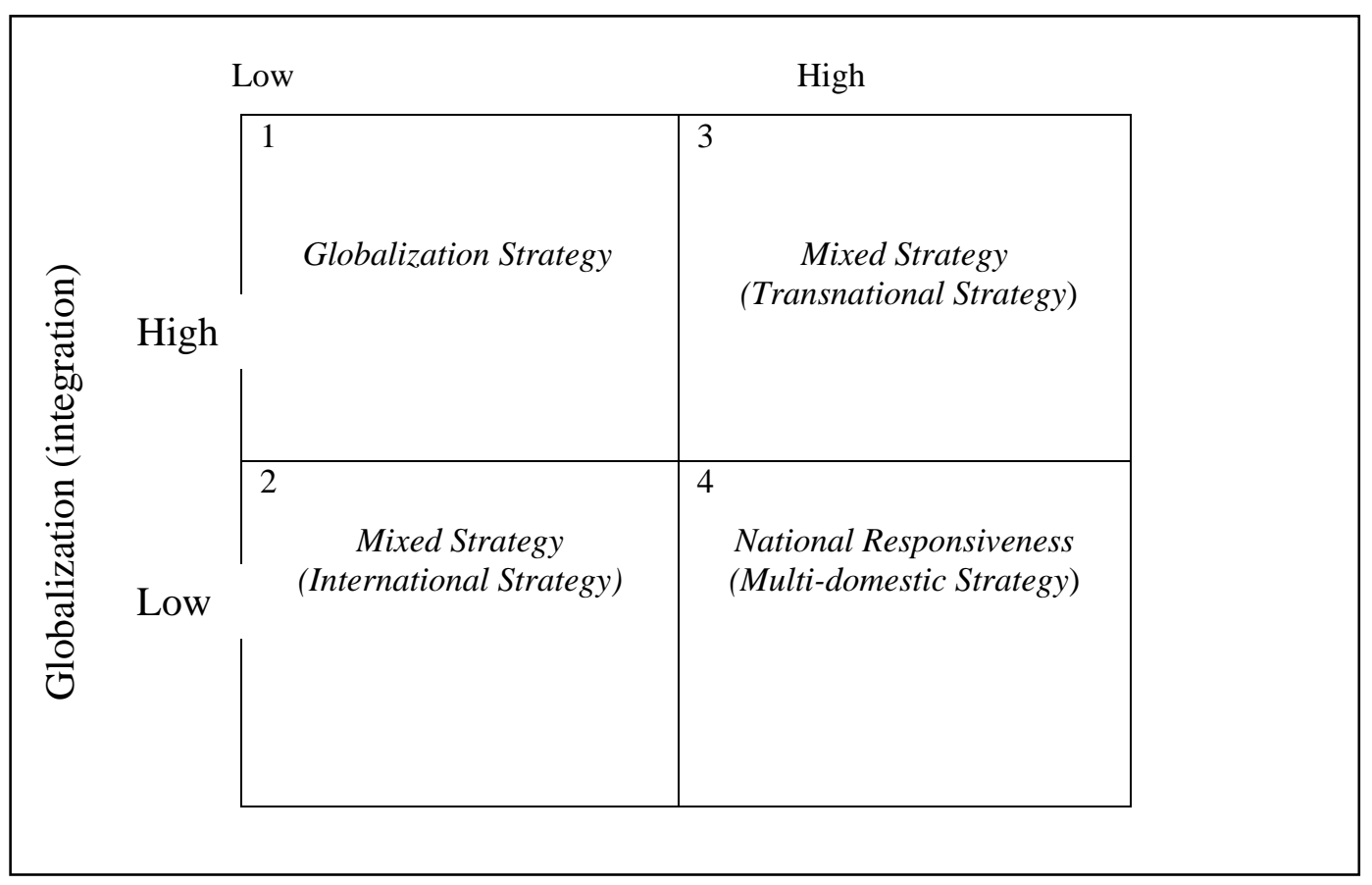

Gambar 1 National Responsiveness (Diferensiasi)

\section{Kuadran 1}

Kebutuhan integrasi tinggi dan kebutuhan akan diferensiasi rendah, dalam skala ekonomi, maka menggunakan globalization strategy dengan kompetisi harga. Pada kuadran ini merger dan akuisisi sering kali terjadi untuk menghasilkan produk dengan biaya yang relatif lebih murah dan kualitas yang sama.

\section{Kuadran 2}

Kebutuhan integrasi dan diferensiasi rendah. Keduanya berpotensi memperoleh skala ekonomi dan mendapatkan sedikit manfaat diferensiasi. Strategi tipikal ditunjukkan dengan meningkatkan standarisasi internasional atas produk dan jasa. Pendekatan ini biasanya dikenal dengan internasional strategy yang membutuhkan sedikit kontrol kualitas yang terpusat, serta pengambilan keputusan terpusat, dan secara simultan menyesuaikan dengan aktivitas negara masing-masing.

\section{Kuadran 3}

Kebutuhan integrasi dan diferensiasi tinggi. Kebutuhan integrasi yang kuat dalam produksi, seiring dengan persyaratan yang lebih tinggi pada diferensiasi regional dalam bidang pemasaran. MNC harus secara simultan menggapai tujuan ini yang dikenal dengan transnational strategy. 


\section{Kuadran 4}

Kebutuhan integrasi tinggi tetapi kebutuhan integrasi rendah. Selain istilah 'national responsiveness', kuadran ini juga dikenal dengan multi domestic strategy. Dalam kasus ini, Niche Company menyesuaikan produknya untuk memuaskan permintaan diferensiasi yang tinggi dan menyampingkan skala ekonomi karena integrasi tidak terlalu penting.

\section{Menjawab Tantangan}

Banyak MNC menjalankan globalization imperative, yaitu satu pendekatan umum (worldwide approach) dalam menjalankan bisnis adalah kunci efisiensi dan efektivitas. Dalam suatu penelitian yang melibatkan penilaian yang ekstensif atas 115 MNC yang besar, menengah, dan 103 perusahaan afiliasi di Amerika, Kanada, Perancis, Jerman, Jepang, dan Inggris, menemukan bahwa mereka menggunakan strategi yang sama di luar negeri seperti yang digunakan di negara asalnya.

Meskipun kecenderungan menggunakan strategi dari negara asal, MNC yang efektif harus secara terus-menerus berusaha memenuhi kebutuhan lokal. Sejumlah faktor yang membantu dalam memfasilitasi kebutuhan ini adalah mengembangkan strategi yang unik untuk setiap kebudayaan yang berbeda termasuk hal berikut.

1. Berbagai macam standar industri dunia seperti dalam penyiaran, pesawat TV harus diproduksi pada country by country basis.

2. Permintaan akan produk yang berbeda (differenciated) secara terus menerus oleh konsumen setempat, seperti kasus barang-barang konsumsi yang harus memenuhi selera setempat.

3. Kebutuhan untuk menjadi "orang dalam”, seperti dalam kasus konsumen yang lebih suka membeli "barang setempat”.

4. Kesulitan untuk mengatur organisasi global, seperti dalam kasus beberapa cabang setempat yang menginginkan lebih banyak desentralisasi namun yang lainnya menginginkan lebih banyak desentralisasi.

5. Kebutuhan mengijinkan cabang untuk menggunakan kemampuan mereka dan tidak dibatasi oleh kantor pusat, seperti dalam kasus cabang setempat yang mengetahui produk yang unggul untuk pasar mereka dan menghasilkan Return On Investment (ROI) yang tinggi dengan output produksi yang terbatas.

\section{Cross Cultural Differences and Similarities}

Tantangan untuk MNC adalah mengenali dan secara efektif mengatur persamaan dan perbedaan ini. Sebagai contoh, cara MNC mengatur bisnis dalam negara asal mereka seringkali harus berbeda dengan cara mereka mengatur bisnis mereka di luar negeri. Setelah mengenali bahaya yang dihadapi oleh MNC jika menjalankan parochialism dan simplification karena perbedaan budaya, diberikan beberapa contoh cultural similarities dan differences dan bagaimana me-manage across culture yang efektif dengan pendekatan kontijensi. Hal itu dapat menyatukan berbagai latar belakang perbedaan kebudayaan agar memaksimalkan hasil kerja perusahaan. 


\section{Parochialism and Simplification}

Parochialism adalah kecenderungan untuk melihat dunia dengan pandangan dan perspektif. Hal itu akan menjadi masalah yang sulit bagi banyak manajer internasional yang sering berasal dari negara maju dan mempunyai keyakinan bahwa pengetahuan mereka lebih dari cukup untuk mengatasi masalah yang timbul dari negara yang lebih terbelakang ekonominya. Banyak manajer mempunyai pandangan itu karena didukung dengan latar belakang pengetahuan dalam mempelajari ilmu management di negara maju.

Simplification adalah proses yang menunjukkan orientasi yang sama terhadap kelompok budaya yang berbeda. Sebagai contoh cara manajer Amerika berinteraksi dengan manajer Inggris sama caranya dia berinteraksi dengan eksekutif Asia. Di sini, lebih diarahkan pada penyesuaian terhadap keadaan lingkungan guna menghindari pertentangan atau konflik dalam organisasi . Para manajer dituntut untuk mengerti berbagai kebudayaan setempat. Berikut ini disajikan enam kebudayaan dasar.

Tabel 1 Lima Kebudayaan Dasar

\begin{tabular}{ll}
\hline Six Basic Cultural Variations & Range of Variations \\
\hline Orientations & Good (changeable/ unchangeable) \\
\hline What is the nature of people? & $\begin{array}{l}\text { A mixture of good and evil* } \\
\text { Evil (changeable/ unchangeable) }\end{array}$ \\
\hline What is the person's relationship to nature? & $\begin{array}{l}\text { Dominant* } \\
\text { In harmoni with nature } \\
\end{array}$ \\
\hline What is the person's relationship to other people? & $\begin{array}{l}\text { Lineal (hierarchic) } \\
\text { Collateral (collectivist) }\end{array}$ \\
& Individualist* \\
\hline What is the modality of human activity? & Doing* \\
& Being and becoming \\
& Being \\
\hline What is the conception of space? & Private* \\
& Mixed \\
& Public \\
\hline
\end{tabular}

Note: * indicates the dominant U.S. orientation

Mengerti budaya suatu negara dalam hal melakukan transaksi bisnis membuat manajer internasional lebih efektif. Sayangnya ketika mereka ditempatkan pada budaya yang asing, mereka tidak mengerti kebudayaan setempat. Akibatnya, mereka salah menginterpretasi apa yang terjadi, khususnya jika ditempatkan di lingkungan yang asing bagi mereka. Sebagai contoh, perbedaan yang terjadi antara kebudayaan di Jepang dengan yang terjadi di Amerika. Orang Jepang mempunyai karakteristik budaya sebagai berikut.

1. Hubungan antarpribadi relatif berlangsung lama dan mempunyai perasaan keterlibatan yang mendalam dengan sesama.

2. Komunikasi biasanya implisit dan setiap pribadi diajarkan untuk menerjemahkan pesan secara tepat sejak kecil. 
3. Orang yang mempunyai otoritas bertanggung jawab secara pribadi atas tindakan anak buahnya sehingga menyebabkan kesetiaan pada atasan dan bawahan.

4. Persetujuan lebih banyak dibuat secara lisan daripada tulisan.

5. Orang dalam dan orang luar (perusahaan) mudah sekali dibedakan dan biasanya orang luar tidak dapat mengakses pada grup inti.

Orang Amerika mempunyai karakteristik budaya sebagai berikut.

1. Hubungan antarpribadi relatif dalam waktu yang singkat mendasar dan tidak menghargai keterlibatan mendalam.

2. Pesan disampaikan secara eksplisit dan setiap pribadi diajarkan untuk menyatakan apa yang diinginkan sejak kecil.

3. Otoritas dibagi ke seluruh sistem birokrasi dan tanggung jawab pribadi sulit ditentukan.

4. Persetujuan lebih banyak dilakukan secara tertulis daripada lisan.

5. Orang dalam dan orang luar tidak dapat dibedakan dengan jelas, lambat laun orang luar didorong untuk masuk dalam grup inti.

\section{Sepuluh faktor kunci kesuksesan MNC sebagai berikut.}

1. Melihat faktor perubahan mereka sebagai perusahaan multinasional dan dipimpin oleh tim manajemen yang berpengalaman dunia.

2. Mengembangkan strategi yang terintegrasi dan inovatif yang membuat perusahaan sulit dan mahal buat perusahaan lain untuk bersaing.

3. Secara agresif dan efektif menerapkan strategi dunia mereka dan didukung dengan investasi yang besar.

4. Mengerti bahwa inovasi teknologi tidak hanya di Amerika dan mengembangkan sistem yang menekankan inovasi teknologi luar negeri.

5. Beroperasi seolah-olah dunia adalah suatu pasar yang besar, bukan pasar yang tersendiri.

6. Mempunyai strutur organisasi yang didesain untuk mengatasi masalah yang unik dan menantang sehingga diperoleh efisiensi.

7. Mengembangkan suatu sistem yang membuat mereka tetap mengetahui perubahan politik di seluruh dunia dan implikasi perubahan ini pada perusahaan mereka.

8. Mempunyai tim manajemen dengan komposisi internasional sehingga dapat merespon perubahan permintaan pasar mereka dengan baik.

9. Mengijinkan direktur luar memainkan peran aktif mereka dalam operasi perusahaan.

10. Diatur dengan baik dan cenderung mengikuti panduan yang penting dalam mempertahankan hubungan yang dekat dengan konsumen, mempunyai struktur organisasi yang ramping, dan mendorong otonomi dan enterpreunarial bagi karyawannya.

\section{Similarities Across Cultures}

Menurut penelitian yang dilakukan oleh Luthan dan temannya, manajer di Rusia juga menjalankan manajemen tradisional, komunikasi, sumber daya manusia, dan hubungan manusia seperti yang terjadi di Amerika. Penelitian itu mirip dengan karakteristik manajer Amerika, yaitu perhatian yang relatif besar diberikan pada usaha mencari hubungan dan komunikasi untuk meningkatkan efisiensi kinerja. 
Di samping persamaan aktivitas manajerial, studi lain di pabrik Rusia yang sama menguki apakah campur tangan modifikasi perilaku organisasi (O.B. Mod) membawa pengembangan performance dalam organisasi USA dan Rusia. Para peneliti menemukan bahwa pendekatan O.B Mod bekerja baik di USA dan memberikan hasil positif di pabrik Rusia. Pada studi lintas budaya lain seperti Korea, Luthans dan temannya menggunakan faktor di USA dan terdapat persamaan dari kedua kebudayaan yang berbeda sebagai berikut.

1. Ukuran organisasi meningkat, komitmen menurun;

2. struktur menjadi lebih berfokus pada karyawan, komitmen meningkat; dan

3. persepsi iklim organisasi lebih positif, komitmen karyawan paling besar.

\section{Many Differences Across Culture}

Contoh yang diberikan oleh Trompenaars adalah bidang sumber daya manusia, dalam studi kasus yang dilakukan perusahaan Shell dengan menggunakan HAIRL system of appraisal. Kelima kriteria dalam singkatan HAIRL sebagai berikut.

1. Helikopter $\rightarrow$ kemampuan untuk mendapatkan pandangan yang luas dari atas.

2. Analisis $\rightarrow$ kemampuan untuk mengevaluasi situasi secara logis dan menyeluruh.

3. Imajinasi $\rightarrow$ kemampuan kreatif dan berpikir "di luar kotak".

4. Realistis $\rightarrow$ kemampuan untuk menggunakan informasi secara realistis.

5. Kepemimpinan $\rightarrow$ kemampuan untuk membangkitkan dan memberikan inspirasi kepada bawahan.

Ketika cabang operasional Shell diminta untuk memberikan prioritas atas kelima kriteria tersebut, hasilnya sebagai berikut.

Tabel 2 Prioritas Lima Kriteria Sistem Operasional Shell

\begin{tabular}{llll}
\hline Belanda & \multicolumn{1}{c}{ Perancis } & Jerman & \multicolumn{1}{c}{ Inggris } \\
\hline \hline Realitas & Imajinasi & Kepemimpinan & Helikopter \\
\hline Analisis & Analisis & Analisis & Imajinasi \\
\hline Helikopter & Kepemimpinan & Realitas & Realitas \\
\hline $\begin{array}{l}\text { Kepemimpinan } \\
\text { Imajinasi }\end{array}$ & Helikopter Realitas & Imajinasi Helikopter & Analisis \\
\hline
\end{tabular}

Dari studi tersebut, cukup jelas bahwa karyawan di masing-masing negara sangat berbeda prioritasnya dalam menerapkan kegiatan operasional management. Perbedaan lain sumber daya manusia adalah masalah gaji, kompensasi, kesamaan pembayaran, dan cuti melahirkan. Berikut ini contohnya.

1. Konsep pembayaran gaji per jam tidak berperan besar di Meksiko. Hukum tenaga kerja mengharuskan perusahaan untuk membayar gaji karyawan 365 hari per tahun. 
2. Di Austria dan Brasil, karyawan yang bekerja lebih dari setahun secara otomatis diberikan cuti 30 hari.

3. Di Kanada mempunyai aturan kesamaan menerima pembayaran gaji antara pria dan wanita.

4. Di Jepang, tingkat kompensasi ditentukan oleh faktor objektif, antara lain umur, lama pengabdian, latar belakang pendidikan, kemampuan pribadi, dan kinerja. Kinerja tidak dihitung sampai karyawan mencapai usia 45 tahun.

5. Di Inggris, karyawan mengijinkan cuti melahirkan sampai 40 minggu, dan perusahaan harus membayar gaji 18 minggu dari jumlah tersebut.

6. Dalam $87 \%$ perusahaan Swedia, Kepala SDM adalah salah satu direktur perusahaan.

Hal tersebut sangatlah berbeda dengan kondisi di USA. Perusahaan USA perlu menyesuaikan gaya bila ingin masuk ke negara tersebut dengan sukses. Perencanaan kompensasi merupakan hal yang sangat penting dalam masing-masing budaya yang berbeda. Berikut ini disajikan gaya kebudayaan yang digunakan pada negara kawasan Asia dan Eropa.

Tabel 3 Gaya Kebudayaan di Negara Asia dan Eropa

\section{CULTURAL CLUSTERS IN THE PACIFIC RIM, EU, AND UNITED STATES}

\begin{tabular}{l|c|c|c|c}
\hline & $\begin{array}{l}\text { Power } \\
\text { Distance }\end{array}$ & Individualism & Masculinity & $\begin{array}{l}\text { Uncertainity } \\
\text { Avoidance }\end{array}$ \\
\hline Pacific Rim & & & & - \\
Hongkong, Malaysia, Philipine, & + & - & + & + \\
Singapore & + & - & + & + \\
Japan & & - & - & + \\
South Korea, Taiwan & + & & & + \\
EU \& United States & + & + & - & + \\
France, Spain & + & - & + & + \\
Italy, Belgium & + & - & + & - \\
Portugal & - & + & + & + \\
Greece & - & + & + & + \\
Denmark, Netherlands & - & + & + & \\
Germany & & & & + \\
Great Britain, Ireland, United & & & & \\
States & & & & + \\
\hline
\end{tabular}

Tabel tersebut memperlihatkan kelompok host yang berbeda budayanya, termasuk negara Asia, EU dan Anglo. Setiap kelompok memerlukan pendekatan yang berbeda untuk memformula strategi kompensasi yang efektif dan setelah menganalisa setiap kelompok, disarankan sebagai berikut.

1. Di negara Pasifik Rim, strategi insentifnya adalah memberi gaji tertinggi pada manajer tingkat senior. 
2. Di Eropa, strategi kompensasi harus sama. Bagaimanapun juga, di Italia dan Belgia, gaji yang lebih tinggi harus dibayarkan pada manajer lokal tingkat senior. Portugal dan Yunani, profit sharing lebih efektif dibandingkan salary tinggi. Denmark, Belanda, dan Jerman, rencana insentif perorangan akan lebih tinggi kegunaannya karena budaya individualisme yang tinggi.

3. Inggris, Irlandia, dan USA penilaian terhadap prestasi individu, penghargaan dan tantangan lebih meningkatkan motivasi. Kompensasi harus sesuai dengan kebutuhan.

Sebagai tambahan, beberapa MNC's menemukan rencana kompensasi yang sangat menarik bagi tenaga kerja lokal tidak ada nilainya bagi anggota tenaga kerja internasional mereka. Contohnya ketika Gillete Company memutuskan untuk menawarkan saham pada 33.000 karyawannya di seluruh dunia, perusahaan menemukan bahwa rencananya tidak global dipandang dari ketertarikan karyawan. Beberapa alasan termasuk pendapatan karyawan rendah dan merasa saham adalah investasi beresiko. Sederhananya tenaga kerja dengan budaya lain sering tidak mempunyai pandangan yang sama mengenai rencana kompensasi seperti tenaga kerja Amerika. Hal tersebut menyebabkan banyak MNC's mengembangkan strategi kompensasi berdasarkan kebetulan yang dicocokkan pada rapat kebutuhan pekerja lokal.

Tabel 4 A Partially Completed Contigency Matrix For International Human Resources Management

\begin{tabular}{|c|c|c|c|c|}
\hline $\begin{array}{r}\text { Recruit } \\
\text { ment and } \\
\text { selection }\end{array}$ & $\begin{array}{l}\text { - } \text { Prepare for long } \\
\text { process } \\
\text { - Ensure that your } \\
\text { firm is “here tto } \\
\text { stay" } \\
\text { - Develop trusting } \\
\text { relationship with } \\
\text { reruit }\end{array}$ & $\begin{array}{l}\text { Obtain skilled labor } \\
\text { from government } \\
\text { subsidized } \\
\text { apprenticeship } \\
\text { program }\end{array}$ & $\begin{array}{l}\text { - Use expatriates } \\
\text { sparingly } \\
\text { - Recuit Mexican } \\
\text { nationals at U.S. } \\
\text { colleges }\end{array}$ & $\begin{array}{l}\text { - Recent public } \\
\text { policy shifts } \\
\text { encourage use of } \\
\text { sophisticated } \\
\text { selection } \\
\text { procedures }\end{array}$ \\
\hline Training & $\begin{array}{l}\text { - Make substantial } \\
\text { investment in } \\
\text { training } \\
\text { - Use general } \\
\text { training and cross- } \\
\text { training } \\
\text { - Training as every } \\
\text { one's responsibility }\end{array}$ & $\begin{array}{l}\text { - Reorganize and } \\
\text { utilize } \\
\text { apprenticeship } \\
\text { programs } \\
\text { - Be aware of } \\
\text { government } \\
\text { regulations on } \\
\text { training }\end{array}$ & $\begin{array}{l}\text { - Use bilingual } \\
\text { trainers }\end{array}$ & $\begin{array}{l}\text { - Careful } \\
\text { observations of } \\
\text { existing training } \\
\text { programs } \\
\text { - Utilize team } \\
\text { training }\end{array}$ \\
\hline $\begin{array}{r}\text { Compens } \\
\text { ation }\end{array}$ & $\begin{array}{l}\text { - Use recognition } \\
\text { and praise as } \\
\text { motivator } \\
\text { - Avoid pay for } \\
\text { performance }\end{array}$ & $\begin{array}{l}\text { - Note high labor } \\
\text { costs manufacturing }\end{array}$ & $\begin{array}{l}\text { - Consider all } \\
\text { aspects of labor } \\
\text { cost }\end{array}$ & $\begin{array}{l}\text { - Use technical } \\
\text { training as reward } \\
\text { - Recognize } \\
\text { egalitarian values } \\
\text { - Use “more work } \\
\text { mor pay” with } \\
\text { caution }\end{array}$ \\
\hline $\begin{array}{r}\text { Labor } \\
\text { relations }\end{array}$ & $\begin{array}{l}\text { - Treat unions as } \\
\text { partners } \\
\text { - Alloe time for } \\
\text { negotiation }\end{array}$ & $\begin{array}{l}\text { - Be prepared for } \\
\text { high wages and } \\
\text { short work week } \\
\text { - Expect high } \\
\text { productivity from } \\
\text { unionized workers }\end{array}$ & $\begin{array}{l}\text { - Understand } \\
\text { changing Mexican } \\
\text { labor law } \\
\text { - Prepare for } \\
\text { increasing } \\
\text { unionized of labor }\end{array}$ & $\begin{array}{l}\text { - Tap large pool of } \\
\text { labor cites } \\
\text { - Lax labor laws } \\
\text { may become more } \\
\text { straight }\end{array}$ \\
\hline
\end{tabular}


Tabel 4 A Partially Completed Contigency Matrix For International Human Resources Management (lanjutan)

\begin{tabular}{|c|c|c|c|c|}
\hline $\begin{array}{r}\text { Job } \\
\text { design }\end{array}$ & $\begin{array}{l}\text { - Incluce } \\
\text { participation } \\
\text { - Incorporate group } \\
\text { goal setting } \\
\text { - Use autonomous } \\
\text { awork teams } \\
\text { - Use uniform, } \\
\text { formal approach } \\
\text { - Encourage co- } \\
\text { worker input } \\
\text { - Empower teams to } \\
\text { make decision }\end{array}$ & $\begin{array}{l}\text { - Utilize works } \\
\text { councils to } \\
\text { enchance worker } \\
\text { participation }\end{array}$ & $\begin{array}{l}\text { Approch } \\
\text { participation } \\
\text { coutiously }\end{array}$ & $\begin{array}{l}\text { Determine } \\
\text { employee's } \\
\text { motives before } \\
\text { implementing } \\
\text { participation }\end{array}$ \\
\hline & Japan & Germany & Mexico & China \\
\hline
\end{tabular}

Tabel 4 Memperlihatkan bagaimana spesifikasi area SDM dapat dianalisis secara kelompok pada basis negara per negara. Contoh, Jepang yang kontras dengan pendekatan USA ditemukan sejumlah perbedaan. Rekrutmen dan seleksi di perusahaan Jepang sering didesain untuk membantu identifikasi individu yang dapat melakukan pekerjaan terbaik dalam jangka waktu panjang. Di USA, orang sering dipekerjakan berdasarkan apa yang dapat mereka lakukan untuk perusahaan dalam jangka waktu pendek, karena kebanyakan mereka akan berhenti atau di - PHK. Jepang menggunakan banyak sekali lintas pelatihan, sementara di USA cenderung menyukai spesialisasi pelatihan. Jepang menggunakan penilaian performance kelompok dan imbalan sebagai kelompok tetapi USA menggunakan penilaian performance manager subordinat dan imbalannya perorangan. Jepang, serikat pekerja merupakan partner namun di USA manajemen dan serikat kerja saling memandang dengan cara permusuhan. Hanya dalam Job Design, Jepang dan USA sama banyaknya menggunakan partisipasi manajemen dan otonomi team work.

Perbedaan tersebut jangan diartikan bahwa SDM suatu negara superior dari yang lain. Kenyataannya, penelitian dari Jepang dan Eropa memperlihatkan perusahan ini mengalami insiden yang tinggi dalam masalah hubungan perorangan daipada perusahaan Amerika, contohnya dalam hal berikut.

1. Personal home-country cukup memiliki keahlian internasional;

2. personal home-country mau bekerja diluar negeri;

3. kesulitan dalam menarik warga negara lokal yang berkaliber tinggi; dan

4. tingginya turn over tenaga kerja lokal.

Sebagai tambahan, dibandingkan dengan MNC's Jepang, MNC's USA sedikit perselisihan dan komunikasi yang lebih baik antara expatriate home-country dengan pekerja lokal dan hanya sedikit komplain oleh pekerja lokal berhubungan dengan keahlian tambahan dalam perusahaan.

Tabel 4 mengidentifikasi dengan jelas pentingnya MNC’s menggunakan pendekatan kontigensi untuk SDM lintas budaya. Tidak hanya terdapat praktek yang berbeda dalam budaya 
yang sama. Disamping pendekatan berbeda yang digunakan dalam negara yang berbeda pula menjadi jelas bahwa asumsi umum dan kebijaksanaan yang lazim tentang praktek SDM di negara tertentu tidak berlaku sama.

Dapat disimpulkan bahwa me-manage lintas budaya memerlukan pengertian pada lingkungan lokal karena asumsi umum yang stereotype tidak berlaku. Perbedaan budaya baru diutamakan dan inilah sebabnya mengapa penelitian lintas budaya dilanjutkan lebih kritis dalam membantu perusahaan mempelajari bagaimana me-manage lintas budaya.

\section{Perbedaan Budaya di beberapa Negara dan Kawasan}

\section{Doing Business in China}

Budaya yang dapat mempengaruhi bisnis di China dapat disimpulkan sebagai berikut.

1. Orang Cina menekankan kepercayaan dan koneksi bersama.

2. Pertemuan bisnis biasanya dimulai dengan minum teh dan percakapan umum tentang perjalanan tamu, penginapan, dan keluarga. Biasanya tuan rumah telah diberikan informasi tentang latar belakang tamu.

3. Jika pertemuan sudah ingin dimulai, tuan rumah akan memberikan tanda, demikian juga jika pertemuan sudah selesai.

4. Jika orang Cina telah menentukan siapa dan terbaik, mereka cenderung berpegang pada keputusannya. Oleh karena itu, mereka lamban dalam merencanakan tindakan tetapi jika sudah dimulai mereka membuat suatu kemajuan yang cukup baik.

5. Dalam negosiasi, asas timbal balik penting. Jika orang Cina memberikan kesepakatan, mereka juga mengharap balasannya.

6. Karena negosiasi dapat membuat mereka kehilangan muka maka orang Cina biasanya menggunakan perantara untuk mengemukakan idenya tanpa merasa malu.

\section{Doing Business in Rusia}

Ada beberapa saran dalam berbisnis di Rusia.

1. Berusaha membangun hubungan pribadi dengan partner bisnis. Kontrak bisnis dan hukum tidak seperti yang berlaku di negara barat, jika terjadi perselisihan tidak terdapat perlindungan yang cukup untuk pihak yang dirugikan karena memerlukan waktu dan usaha membawa ke pengadilan, sehingga yang dapat diandalkan adalah persahabatan.

2. Gunakanlah konsultan lokal karena semua aturan bisnis telah berubah banyak dalam tahun belakang ini. Sebaliknya, gunakan konsultan yang selalu berada di Rusia sepanjang waktu dan mengerti iklim bisnis setempat.

3. Perhatikan etika bisnis. Etika bisnis di Amerika tidak selalu sama dengan etika bisnis di Rusia. Sebagai contoh, di Rusia sudah merupakan tradisi untuk memberikan hadiah kepada rekan bisnisnya, sedangkan di Amerika hal ini merupakan penyogokan.

4. Bersabarlah. Jika ingin mengerjakan sesuatu di Rusia, akan memakan waktu berbulan-bulan. Orang yang biasanya mengerjakan sesuatu dengan tergesa-gesa biasanya mengalami kekecewaan.

5. Tekankan pada eksklusivitas. Orang Rusia biasanya menyukai pertemuan eksklusif dan biasanya bernegosiasi dengan banyak perusahaan sebelum memutuskan salah satunya. 
6. Ingat bahwa hubungan pribadi penting. Orang Rusia senang melakukan bisnis dengan bertatap muka, jadi jika mereka menerima fax atau surat mereka biasanya meletakkan pada mejanya tetapi tidak merespon, mereka menunggu usahawan menghubungi dan membuat pertemuan pribadi.

7. Simpan informasi keuangan. Jika orang barat melakukan bisnis dengan partnernya biasanya membagi informasi keuangan dengan mereka dan mengharapkan sebaliknya. Orang Rusia menunggu sampai merasa aman untuk membagi informasi keuangan mereka.

8. Lakukan penelitian terhadap perusahaan. Dalam melakukan persetujuan dengan partner Rusia, akan sangat membantu jika kita mendapatkan informasi tentang perusahaannya, hirarki, dan bagaimana mereka menjalankan bisnisnya. Informasi ini akan sangat membantu mereka untuk membangun hubungan yang baik.

9. Tekankan keuntungan bersama. Ide barat untuk menciptakan "win-win” dalam negosiasi juga berlaku di Rusia. Partner potensial ingin mengetahui keuntungan mereka jika mendirikan usaha bersama.

10. Klarifikasi istilah-istilah. Persetujuan bisnis di Rusia merupakan sesuatu yang baru, sehingga perlu dicek ulang dan meyakinkan bahwa pihak lain benar-benar mengerti proposal, mengetahui apa yang mereka harapkan dan menyetujuinya.

\section{Doing Business in India}

Jika melakukan bisnis di India, ada beberapa kebiasaan yang sangat berguna, antara lain sebagai berikut.

1. Dalam pertemuan harus datang tepat waktu.

2. Sebaiknya tidak menanyakan pertanyaan pribadi kecuali kalau rekan bisnis merupakan rekan dekat atau teman.

3. Gelar merupakan hal yang penting sehingga orang yang mempunyai gelar doktor atau profesor harus dicantumkan.

4. Penunjukkan kasih sayang terhadap sesama dipertimbangkan tidak sopan sehingga tidak disarankan untuk menepuk punggung atau menyentuh orang lain.

5. Menunjuk seseorang biasanya menggunakan dagu.

6. Ketika makan atau menerima barang biasanya menggunakan tangan kanan karena tangan kiri dipertimbangkan sebagai tangan yang kotor.

7. Menawar barang dan jasa merupakan hal yang biasa, lain dengan tradisi barat yang menganggap penawaran sebagai tindakan yang kasar.

\section{Doing Business in France}

Banyak perusahaan Prancis mempunyai sentralisasi yang tinggi dan mempunyai struktur yang kaku sehingga pengambilan keputusan memerlukan waktu yang lebih lama. Tambahan karakteristik kebudayaan akan membantu menjelaskan kesulitan-kesulitan yang akan ditemui orang luar Prancis seperti berikut.

1. Jika berjabat tangan dengan orang Prancis, jabatlah tangan dengan cepat dan memegang dengan kuat. Menjabat tangan dengan diayunkan seperti yang berlaku di Amerika dipertimbangkan sebagai tidak berkebudayaan.

2. Sangat penting untuk datang tepat waktu pada pertemuan sosial.

3. Jika sedang makan, boleh membicarakan hal yang menyenangkan tetapi pertanyaan pribadi atau yang berhubungan dengan uang jarang dibicarakan. 
4. Kerapian dan selera sangat penting sehingga jika ingin bertemu dengan usahawan harus berusaha keras untuk "berbudaya" dan rapi.

\section{Doing Business in Arab Countries}

Panduan untuk melakukan bisnis di negara Arab antara lain sebagai berikut.

1. Jangan pernah menunjukkan superioritas karena membuat pihak lain merasa inferior. Bagaimanapun bagusnya hasil kerja seseorang, jangan pernah menyombongkan diri atau menunjukkan pentingnya diri sendiri.

2. Orang tidak boleh menonjolkan diri sendiri atas usaha bersama.

3. Banyak hal yang dilakukan dengan channel administrasi negara. Orang yang mengerjakan sesuatu di luar channel tersebut dapat dikelompokkan sebagai tidak menghargai hukum dan institusi negara.

4. Koneksi sangat penting dalam menjalankan bisnis. Usahawan yang mempunyai koneksi yang bagus dapat bekerja lebih cepat jika dibandingkan dengan orang yang tidak mengetahui sistem masuk dan keluar.

5. Kesabaran sangat dibutuhkan dalam transaksi bisnis. Pertimbangan waktu sangat penting dibuat dalam semua negosiasi sehingga mencegah seseorang dalam berusaha untuk mendapatkan persetujuan yang cepat.

6. Keputusan penting harus dihadiri oleh orangnya sendiri, tidak dengan surat-menyurat atau dengan telepon. Jika terdapat banyak orang memberikan masukan dalam rapat pengambilan keputusan final, biasanya keputusan akhir dibuat oleh atasan.

Terdapat banyak perbedaan kebudayaan antarnegara sehingga bagi para menajer yang berskala internasional, perlu melengkapi dengan pengetahuan tentang berbagai kebudayaan di berbagai negara. Hal itu dilakukan untuk mempermudah pengembangan industri atau usaha yang akan memberi hasil yang optimal dalam hal return yang akan diperoleh. Dengan banyaknya pengetahuan mengenai berbagai kebudayaan antara negara akan memperkaya seorang manegement tarai internatinal dalam membuat keputusan yang sesuai dengan kondisi lingkungan dia berada untuk mempermudah komunikasi dan interaksi antara personil ditempat manager tersebut berada .

Kemampuan memahami berbagai latar belakang kebudayaan akan menciptakan satu situasi kerja yang kondusif di tempat kerja. Dengan adanya suasana kerja yang konduksif akan memberikan hasil yang optimal bagi perusahaan. Bagi manajer yang berhasil menerapkan kebijakan perusahaan di berbagai negara, akan memperoleh image positif dari berbagai perusahaan berskala dunia sehingga sangat dapat dipastikan menghasilkan pribadi eksekutif yang akan diburu oleh para pemilik modal untuk mengelola perusahaan mereka.

\section{PENUTUP}

\section{Simpulan}

1. Salah satu hal utama dalam menghadapi MNC, mereka ingin melakukannya seperti di negara mereka sendiri. Globalisasi harus diberikan perhatian yang lebih dari national responsiveness 
atau sovereignty walau pada tahun belakangan ini, di bawah strategi manajemen internasional, globalisasi telah terbentuk, fokus pada lokal dapat membawa keuntungan. Beberapa faktor yang patut masuk hitungan untuk strategi baru (a) perlu dibagi dalam standar worldwide; (b) pentingnya diferensiasikan produk untuk pasar lokal; (c) perlunya menjadi orang dalam daripada tergantung kebijakan ekspor; dan (d) perlunya memberikan sumbangan yang lebih berarti untuk merespon kondisi lokal.

2. Satu tantangan utama ketika berhadapan dengan masalah cross-cultural harus menyelesaikan parochialism dan simplification. Parochialism adalah kecenderungan untuk melihat dunia dengan pandangan dan perspektif. Simplification adalah proses yang menunjukkan orientasi sama terhadap kelompok budaya yang berbeda. Permasalahan lain ketika mereka melaksanakan dengan cara sama untuk pasar luar negeri dan pasar domestik. Penelitian menunjukkan pada beberapa kasus pendekatan ini efektif, walau efektifnya manajemen crossculture lebih banyak meminta pendekatan berbeda dengan di rumah. Ini merupakan salah satu bukti utama diperlukannya manajemen sumber daya manusia. Recruitment, selection, training dan kompensasi sering dibawakan dengan berbeda pada setiap negara dan yang berlangsung di United State mungkin memiliki nilai batasan berbeda dengan negara dan daerah geografis yang lain.

3. Melakukan bisnis di bagian berbeda dari dunia memerlukan pengakuan dan pengertian perbedaan budaya. Beberapa perbedaan melibatkan tugas kemasyarakatan terhadap waktu, status, kontrol dari pengambilan keputusan, penyelesaian personal dan kerja itu sendiri. Tipe berbeda dari perbedaan budaya membantu menjelaskan kenapa efektifitas manajer di China dan Rusia sering berbeda dengan Prancis dan mengapa keberhasilan dengan gaya United State akan tidak ideal di negara Arab.

\section{DAFTAR PUSTAKA}

Cropo, Richley. 2001. Cultural Antropologi. $5^{\text {Th }}$ Edition. Logan.2001. Utah State University.

Johnson, Johny K. 2001. Global Marketing. 2nd edition. Georgetown University: Irwin McGrow-Hill.

Tozer, Steven. 2001. School and Society. $4{ }^{\text {th }}$ Edition. University of Illinois Chicago and Paul Violos, University of Champaign and Guy Senese. Nothern Arizona University. 